\title{
Nursing and Medical Students' Perceptions of the Rehabilitation Medicine Course Unit: A Case Study of Mbarara University of Science a nd Technology.
}

\author{
Lillian Nabacwa ${ }^{a}$ \\ a Department of Nursing, Mbarara University of Science and Technology
}

\begin{abstract}
\end{abstract}

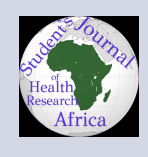

Background: ${ }^{a}$

Physical and Rehabilitation Medicine is a medical specialty concerned with the improvement of functioning through diagnosis and treatment of health conditions, reduction of impairment, and prevention and treatment of complications. In an era of an increasing number of debilitating and disabling conditions arises the need for exposure of medical students to a goal of reducing the impact of disabling conditions and socially integrating the individuals suffering from the after-effects of these diseases. However, for the future development of this specialty, there is a need to explore students' attitudes and perceptions.

Methodology:

A qualitative descriptive design was employed in the study. A purposive sampling method was used to recruit 18 participants who had done the Rehabilitation Medicine course unit in the year 2019/2020. Data was collected using an interview guide. Data analysis was carried out using content analysis basing on existing themes.

Results:

Basing on already existent themes which included: - Resources for Rehabilitation Medicine, Activities are done during Rehabilitation Medicine Training, Support provided during Rehabilitation Medicine Training and Evaluation carried out during Rehabilitation Medicine, the study revealed students' report about the reading resources that were not well provided, appreciated the activities done during training and commended the lecturers for the optimum support rendered to them during training. They however expressed disagreement with the evaluation method of post-lecture tests as they reported they were conducted with bias and only targeted students that understand information firsthand from the lecture in class.

Conclusion and recommendation : Students' perceptions towards rehabilitation Medicine are generally positive. The evaluation method of post-lecture tests that is formative nature would be much appreciated and positively perceived if the feedback is provided in order for students to carry out self-assessment.

\footnotetext{
${ }^{a}$ Email: lillianlutaaya@gmail.com

Received: 29th/12/2020 Accepted:

5th/02/2021 Journal of Community

Health and Behavioural Sciences
} 


\section{Background}

Physical and Rehabilitation Medicine is a medical specialty concerned with the improvement of functioning through diagnosis and treatment of health conditions, reduction of impairment, prevention, and treatment of complications (WHO, 2014). This specialty has been noted to equip students with the knowledge, skills, and attitudes necessary for the assessment and management of individuals and families with disabilities (Vlak et al., 2004). Whereas Rehabilitation medicine is considered traditionally unpopular with medical students (Gibson et al., 2010) and with fewer medical schools having a department for rehabilitation and a residency program (Brane et al., 2016), many authors have consistently put forward the need for its inclusion in the medical curriculum and emphasized its teaching to all healthcare professional students including nursing and physiotherapy in order to increase their knowledge in this area (Grutenbrunner et al., 2010, Khosrawi et al., 2018).

Research has noted that there is an increasing need to expose medical students to the principles of rehabilitation medicine due to the burden of debilitating diseases and injuries that come with long-term disability (Grutenbrunner et al., 2017). One of the studies indicated that the level of knowledge of medical students in Physical and Rehabilitation medicine was low although their attitudes were found to be of a high level and thus deemed it necessary that the course unit be added to the curriculum of medical students (Khosrawi et al., 2018).

In an era of an increasing number of debilitating and disabling conditions arises the need for exposure of medical students to a goal of reducing the impact of disabling conditions and socially integrating the individuals suffering from the after-effects of these diseases. This often requires preventive measures, setting a diagnosis, function assessment on top of the provision of treatment, and rehabilitative management (Grutenbrunner et al., 2017).

It's a specialty that not only needs to be taught to medical students but also other healthcare profession students in order to ensure that students become aware of each profession's roles in a rehabilitation team. In addition, this enables its usefulness in a number of healthcare settings such as post-acute services, emergency, and rehabilitation centers where different health care professions could be seen (Vlak et al., 2004; Grutenbrunner et al., 2017). This field provides students with knowledge, skills, and attitudes which are necessary for both assessment and management of persons with disabilities and enhances their awareness of psychological and social issues that surround people with disabilities (Vlak et al., 2004).

Research has indicated negative perceptions of this specialty of rehabilitation medicine by medical students where knowledge levels have been found to be below average in the majority of the students despite the fact that some students had shown a highly positive attitude towards it, for example, Khosrawi et al., (2018) indicated that in his study, students had a low level of knowledge in the field although they exhibited a positive attitude.

The negative perceptions have been attributed to inconsistent curriculum, short time allocated to the course, and lack of early exposure of students to the existence and importance of pursuing the specialty (Gibson et al., 2010, Khosrawi et al., 2018). However, Guiotoku et al., (2018) indicated from their study that students' (80\%) perceived the specialty as an important discipline in medical training. Thus, stressing the fact of retaining the specialty within the curriculum. Gibson et al., (2010) indicate the need to evaluate students' knowledge and perceptions regarding the specialty if this underrepresented specialty is to develop in the nearby future.

At Mbarara University of Science and Technology, the MUST, Rehabilitation medicine course was introduced in the year 2008 and was initially taught to Bachelor of Medicine and Surgery Students alone. Later, it was incorporated into the Bachelor of Science in Nursing and Bachelor of Science in NursingCompletion programs curricula in 2012. It is a 3credit unit course taught in the 4th year, the first semester for both nursing and medical and second year completion nursing students. The course is taught once a week for two hours by two lecturers in the Physiotherapy department of MUST. The mode of assessment is by post-lecture tests, student group presentations, individual case writeups, and End of Semester written examination.

Existing literature has for long expressed the need to explore students' perceptions towards specialties especially rehabilitation medicine amongst student groups if such courses are to develop in the future (Gibson et al., 2010). In addition, studies have shown that student perceptions towards a subject can negatively affect their attitudes and 
consequently their performance (Ferreira et al., 2008). Whereas the general performance of nursing and medical students in rehabilitation medicine at MUST has been good since its introduction in their curricula, there hasn't been an evaluation on perceptions of these students towards the course at MUST (Rehabilitation medicine course records, 2020). This study, therefore, aims at exploring the perceptions of nursing and medical students towards rehabilitation medicine course at MUST.

\section{METHODOLOGY}

\section{Study Area}

This study was conducted at Mbarara University of Science and Technology (MUST) which is located in South-Western Uganda along the Mbarara- Kabale highway. It is about 267 kilometers from Kampala along Kampala- Kabale highway. MUST constitute of four faculties of Which Faculty of Medicine is one. Faculty of medicine consists of six programs which include: - Bachelor of Science in Nursing, Bachelor of Science in Medicine and Surgery, Bachelor of Pharmacy, Bachelor of Pharmaceutical Sciences, Bachelor of Medical Laboratory Sciences, and Bachelor of Physiotherapy.

\section{Study Design}

The study used an explorative descriptive design using qualitative methods of data collection. This was chosen because it explained and described the phenomenon. It was also chosen because it is suitable for in-depth exploration of topics/issues of interest (Burns and Groves, 2003).

\section{Target population}

The study participants were students in the Faculty of Medicine at MUST who were pursuing a Bachelor of Science in Nursing-direct entry (BNS) in the fourth year, Bachelor of Science in Nursingcompletion (BNC) in their second year, and Bachelor of Medicine and Bachelor of Surgery (MBChB) in the fourth year. These were chosen because they had all done the Rehabilitation Medicine course unit in the academic year 2019/2020.

\section{Sampling procedure}

The study used a non-probability sampling method of purposive sampling method targeting nursing and medical students who had just freshly done Rehabilitation Medicine in the academic year 2019/2020. This method was chosen because it selected individuals according to their specific knowledge and experience about a phenomenon with an aim of sharing knowledge (Steubert and Carpenter, 2011). Having just done the course unit in their 1st semester of the fourth and second year, these students were assumed to be in a position to share relevant perceptions of the specialty from an informed point.

\section{Sample size determination}

The sample size was determined by data saturation at a point where no new information could be extracted from the sampling unit (Burns and Groves, 2003). In addition, according to Polit and Beck, 2012), a sample size of 6-12 is considered sufficient as the emphasis is put on the richness of the data. A sample size of 18 was used since the study involved participants from two different groups. Three focus group discussions were conducted and constituents of each group areas in the table below:

\section{Inclusion criteria}

The selection of study participants was limited to students who had done Rehabilitation Medicine in the year 2019/2020 who included: -

Only those who were available at university during data collection.

Fourth-year medical and final year nursing students who had done Rehabilitation Medicine in the academic year 2019/2020.

\section{Exclusion criteria}

Those who were very sick to take part in the study were excluded from the study.

\section{Data Collection Tool}

The Focus Group interview guide was used as the data collection tool. The Interview guide was chosen because the study sought to explore Nursing and Medical Students' perceptions towards Rehabilitation Medicine which could be best answered using an interview guide.

\section{Data collection procedure}

Upon obtaining the ethical clearance from the relevant offices and consent from the participants, data were collected using an interview guide. Each Focus Group Discussion lasted for about 35-50 minutes. The researcher asked questions that were relevant to the study and an audio recorder was used to record the participants' responses. All participants were informed that there was no right or wrong answer. The participants were given equal opportunities to participate in the FGD. Each participant was given a code that was mentioned by the researcher when conducting the FGD. The participants were informed that they should feel as 
Table 1. Composition of the focus groups done in the study.

\begin{tabular}{llll}
\hline Name of FGD & Number of males & Number of females & Course \\
FGD 1 & 5 & 1 & BNS 4 \\
FGD 2 & 5 & 1 & MBchb 4 \\
FGD 3 & 0 & 6 & BNC 2 \\
\hline
\end{tabular}

free as possible and that only one person would be allowed to speak at a time. The participants were encouraged to keep the proceedings of the discussions to themselves and not share about them. The participants were informed that they were free to withdraw from the study at any time. To ensure participants' privacy and confidentiality, the researcher conducted the interviews in a neutral quiet environment which was the participants' hostels and at their convenient time to ensure that they freely express themselves without any fears.

\section{Data analysis}

This was done by using content analysis basing on already existent themes from the conceptual framework. The focus group was considered as the unit of analysis. The researcher began this process by listening to audio recordings of the interview and transcribing interviews from tapes to paper. This was followed by reading and rereading through the transcripts to get the general idea and understanding of the students' perceptions and highlighting meaning units as emphasized by Vaismoradi et al., (2016). The researcher followed the steps of data analysis as outlined below according to O'Connor and Gibson (2003): -

Organizing the data which was done by going back to the interview guides, identifying and differentiating the questions being answered as important or essential. This was done by first looking at how the responses of the participants were relating to the research question and then also finding out ideas and categories that were emerging under the different themes and how they were relating to the research question. The ideas and categories were charted for easy review by the researcher.

Finding and organizing ideas, categories under the four themes. This was done by finding out recurring and specific ideas that arise from responses to the research question and the researcher kept a list of these ideas. In addition, the researcher took note of words or phrases that were used by the participants which were also further useful in understanding their perceptions. These phrases or words once identified were organized into codes and then further into categories.

Ensuring the reliability and validity of data analysis and findings which was done by going back to individuals who participated in the study and confirmed their responses.

Finding possible and plausible explanations for the findings which were done by summarizing findings and themes, looking to see if they were as expected based on literature if there are major deviations from literature, and how similar or different they were from literature.

\section{Rigors of the study}

The rigor of the study was achieved by maintaining or ensuring the trustworthiness or believability of the study. The four criteria were used to ensure trustworthiness and they include: - credibility, dependability, transferability, and Confirmability as suggested.

Credibility which refers to the confidence in the truth of findings as judged by participants and others according to (Polit and Beck, 2006) was achieved by using the purposive sampling method and sticking to the inclusion and exclusion criteria, pre-testing the data collection tool, and prolonged engagement by giving sufficient time during interviews.

Dependability which is defined as the stability of the data over time and conditions according to (Polit and Beck, 2006) was achieved by careful listening to recorded responses and consulting study participants to confirm their information and research findings.

Transferability is defined as the extent to which findings can be transferred to other settings. This was achieved through the thick description of the setting and/or participants and by allowing each participant to tell his/her independent or individual perceptions exhaustively until no new information is aired out. 
Confirmability which is defined as the neutrality of the data or analysis by Polit et al., (2006) was obtained by including narrative quotes in the final study findings.

\section{Ethical considerations}

The research proposal was submitted to the Faculty Research Committee for approval. The researcher obtained permission by receiving an introductory letter from the Head of Department nursing which was passed on to the Dean of Students for permission to collect data. The study was fully explained to those who met the inclusion criteria and were given codes to maintain confidentiality. Participants were asked to sign consent forms before participating. The participants were consented before enrolling them into the study. The participants were reminded and assured that participation was voluntary and that they were free to withdraw from the study at any time.

\section{Dissemination of results}

Study results will be submitted to the Faculty of Medicine, specifically the Department of Nursing in partial fulfilment for the award of a Bachelor's degree of science in nursing at MUST, a copy submitted in the university library for future reference and study findings.

\section{Results of the study Socio-demographic information}

A total of three focus groups was conducted. Each focus group constituted of six participants. With regard to social demographics, there were more males than females. The percentage of males that participated was $55.5 \%$. The age range was 22 43. The majority of the participants were nursing students accounting for $66.6 \%$ of the total participants. The summary of the social demographics has been presented in Table 2 below:-

\section{THEMES AND CATEGORIES ACCORDING TO STUDY}

Theme One: RESOURCES FOR REHABILITATION MEDICINE

Under this theme, two categories emerged and they include:- 'Sufficient teaching resources' and 'Insufficient reading resources'.

\section{Sufficient teaching resources.}

The participants reported that the teaching aids were sufficient in a way that lecturers tried their level best to bring all the materials required for students to understand like balls, assistive devices like wheelchairs, and walking sticks. They report that these were fundamental in their understanding of different topics that had been taught. The participants said,

"....the teaching resources were sufficient, especially in the lectures. Those resources, they used to bring the resources, machines per the lectures... (Male, Nursing student, FGD1).

"....... had all the learning materials that I would really need. Because she would bring variety, a variety of learning materials. If it meant balls to go ( Group: jurgle), yeah, they would be there. If it meant wheelchairs for patients to sit on and then she teaches us how to wheel the patients, she would do. So the learning Aaah.teaching materials, the learning resources were available........" (female, Nursing student, FGD3).

"...... there's exposure to materials and equipment and all that as concerned with teaching......" (male, Medicine student, FGD2).

\section{Insufficient reading resources}

Some participants however expressed disappointments as regards the reading materials like notes, textbooks, online reference sites which they said were insufficient and non-accessible. Some participants said,

$"$ "...I wanted to comment on the references. Yes, she used to project work. She had everything to teach us, the teaching aids but she used like, she couldn't give you time to even copy what is on the what, projected and again the website she gave us, some of us opened the notes were not even downloading. She would again refer you to another website so they were not notes....."(Female, Nursing student, FGD3).

"........ when you go to the library, I found it hard to search for some books for Rehabilitation and even on the internet, they were very scarce and knowing some, you would find that you have to first pay. So the resources like reading materials, they were not sufficient......" (male, nursing student, FGD1).

"...... the website she gave, when you enter, it asks you for a username and the username she gave, even if you enter, it will not work.....(female, nursing student, FGD3).

Theme Two: ACTIVITIES DONE DURING REHABILITATION MEDICINE TRAINING

Under this theme, two categories emerged and include:- 'Various activities' and 'lack of a choice'.

\section{Various activities;}

Participants reported that there were a number of activities that were done during the training and they included demonstrations, group discussions, 
Table 2. Socio-demographic characteristics of participants atMbarara University of Science and Technology.

\begin{tabular}{llll}
\hline S/no & Variable $(n=18)$ & Number & Percentage(\%) \\
1 & Age 20-29 30-39 40-49 & 1341 & 72.222 .25 .5 \\
2 & Sex Male Female & 108 & 55.545 .5 \\
3 & Year of study Four Two & 126 & 66.733 .3 \\
4 & Course/Program Nursing Medicine & 126 & 66.633 .3 \\
\hline
\end{tabular}

Table 3. Themes and Categories from the study

\begin{tabular}{|c|c|c|}
\hline \multicolumn{2}{|c|}{ S/no Theme } & Categories \\
\hline 1 & $\begin{array}{l}\text { Resources for } \\
\text { Rehabilitation Medicine } \\
\text { Training }\end{array}$ & - Sufficient teaching resources $\bullet$ Insufficient teaching resources \\
\hline 2 & $\begin{array}{l}\text { Activities done during } \\
\text { Rehabilitation Medicine } \\
\text { Training }\end{array}$ & - Various activities. • Lack of choice. \\
\hline 3 & $\begin{array}{l}\text { Support provided during } \\
\text { Rehabilitation Medicine } \\
\text { Training }\end{array}$ & $\begin{array}{l}\text { - Varied and competent teaching methods. • Student involvement. • } \\
\text { Response to inquiries. }\end{array}$ \\
\hline 4 & $\begin{array}{l}\text { Evaluation in Rehabilitation } \\
\text { Medicine Training }\end{array}$ & $\begin{array}{l}- \text { Evaluation required understanding. } \bullet \text { Encouragement of cram work. } \bullet \\
\text { Bias in the evaluation } \bullet \text { Difference among students. } \bullet \text { Lack of feedback }\end{array}$ \\
\hline
\end{tabular}

role-plays which were sufficient and enabled students to grasp what was being taught.

The participants said,

".....There were a number of activities and I believe they were good because whatever they would teach us in theory, they would make sure they try it out in the practical bit (pause), instantly and that would help us grasp the content." (Male, Nursing student, FGD1).

".....during the lectures, they did enough activities, the different demonstrations and there they involved students to engage them to apply what they had studied in theory bit of it........"(Female, Medicine student, FGD2).

"......the activities that were done were okay because they helped people to learn. Teaching is not all about standing in front of people and you give them matter but these things, the role plays, the discussions......" (female, Nursing student, FGD3).

\section{Lack of choice:}

They however reported that these activities like role plays, demonstrations were not well conducted because students were not given a chance to volunteer in these activities but were instead imposed on them unwillingly and this could spark anxiety amongst students as said,

"...let me even just call it role play because you find, let me give an example, there was a situation where we had to make someone pretend as if the leg is not fine. So to some people, to me, role play I would say is hell because I can't manage it, and since she wasn't giving people the chance to choose, that made some people even start hating that bit of demonstration."(Male, Nursing student, FGD1).

"....... that activity planned for a group are far much important more than the typical teaching. They are so much good if you have the passion to do them but it becomes much more difficult especially when you are not prepared and you are chosen to say a thing........" (female, Nursing student, FGD3).

"....there's that issue where someone is forced to demonstrate yet its meant for an educative purpose. They would say come do this but if you don't know it, it would be as if it's a crime..." (male, nursing student, FGD1).

"......it was a bit challenging in that the lecturer could just land on you and choose you as a participant or she could just get the attendance list and reads you. This thing had a way it could bring up anxiety in students..yeah..students would be on tension......." (female, Medicine student, FGD2).

"......... you would find somebody would be picked from nowhere and they don't even know what to say so there's that feeling that you get. Really, it would be good if she was asking any volunteer to take us 
through this because there are some people who are always scared, anxious ......." (male, nursing student, FGD1).

Theme Three: SUPPORT PROVIDED DURING REHABILITATION MEDICINE TRAINING.

Under this theme, three categories emerged including- 'Varied and competent teaching methods', 'Student involvement', and 'response to inquiries'.

\section{Varied and competent teaching methods}

The participants reported that they felt well supported during class sessions where the lecturer would employ all the necessary methods to ensure that students understand. Some of the participants said,

"........ I think the support was given for example in instances where they would teach us about...they called them Assistive devices. Yeah, they would make sure they bring them and we would look and touch them. It's not like they would just stop at describing them in theory, but they made sure they bring them. And they took their time to teach us how to use them. I think that's all support...."(Male, Nursing student, FGD1).

"...... I think she used all the competent methods during her lecture. I really appreciate....." (Female, Nursing student, FGD3)

\section{Student involvement:}

The participants further added that the lecturers tried their level best to involve and engage everyone during class sessions. Some of the participants said,

".... Even me I think, they tried their level best to engage everyone when teaching because when we are to remember, the muzungu tried to engage you even if you were inactive, she would try to pick you randomly hence engaging everyone. Hence to me, I think no one was left out during her teaching and that is some good support" (Male, Nursing student, FGD1).

"...... She did, she really had her work at hand, she really had what she needed to instruct and she really did the best she could. She at..they were times when she would climb tables, try to silence the class, trying to demonstrate how certain things need to be done...." (Female, Nursing student, FGD3).

"......liked involving everyone, engaging everyone and they always asked questions, say they gave room for questions. They really wanted everyone to participate. They wanted to draw everyone closer......." (Male, medicine student, FGD2).

Response to inquiries;
The participants reported that the lecturers are supportive in a way that they would respond to student's inquiries like emails and ensure that even when students had assignments, there would be someone at the office ready to receive their work. Some participants said,

"..... I also realize that she used in any case, if at all you would send an email, she would reply. These are people who always show that they are interested in. They would send and show a reply every time you sent work... " (Male, Nursing student, FGD1).

"...... every time she gave an assignment, there was always someone waiting for you in the physiotherapy department either to sweetly receive your work or even if you went toward, people would be knowing that you would be there. So the staff would always cooperate with you...." (Male, nursing student, FGD1).

Theme Four: EVALUATION DONE DURING REHABILITATION MEDICINE TRAINING

Under this theme, five categories emerged which include:- 'Evaluation required understanding', 'Encouragement of cram work', 'bias in evaluation', 'Difference among students,' lack of feedback'.

\section{Evaluation required understanding}

The participants described the method of evaluation of post-lecture tests as useful in ensuring that students understand what is being taught in class. Some of the participants said,

"....the assessment was fine. It was actually more tactic and it would bring out people's thinking capacities and all that....." (female, nursing student, FGD1).

"....I think they were really good because even if you look at the nature of how they are given, they really looked good. They were not things to cram about because even if you could write everything in the lecture, it was about finding out actually what you have understood from the lecture...."(Male, medicine student, FGD2).

\section{Encouragement of cram work.}

A number of participants however expressed that they felt the post-lecture tests encouraged cram work instead of understanding for some of the students. Some participants said,

".... People actually would cram because you only need to say the right answer. When you say the wrong answer, you may get a retake. So the post-tests then ceased to be important because people crammed and they forgot thereafter...." (Male, medicine student, FGD2).

".....Giving me a test at the end of the lecture is like you are testing my cramming ability. I would leave all 
those things in the lecture room. If you ask me, I would be like we have covered this, so you are not testing my ability to remember but how to cram....."(Male, nursing student, FGD1).

\section{Bias in evaluation;}

Participants also reported that the tests were a little biased since students weren't provided with the same exact conditions as regards the test. Some participants said,

" ...l think even the continuous assessment was somehow biased because every time we would enter a lecture, the first people to come in would be given papers, then the next people, the ones I would call late comers, their papers would be marked with red. Now, I would just wonder why the papers were marked with red meaning their marks would be deducted like their marks would be reduced from the number of marks they would be, would've got." ( Female, nursing student, FGD3).

".....those guys who would come early, they would get papers with something labeled on them and then those guys who would come late, they would also be labeled indicating late and this determined the marks each one would get and this one affects someone's grades at the end....." (Male, nursing student, FGD1).

\section{Difference among students}

The participants also expressed disagreement with the post-lecture test because they felt that it was geared towards particular kinds of students especially those who understand firsthand from class and argued that students are different and hence understand at different rates and in different ways. Some of the participants said,

"........me I agree people are very different. So some people they can grasp after hearing the contents but others, there are some people who can tell you..me when I go to class, I just go to fill the space and chairs because even if you give me a paper out of class, I can't answer anything minus grasping on my own. So if she was targeting people who were grasping immediately, then she's leaving some people behind...." (Male, Nursing student, FGD1).

".......everyone, they have their own way of understanding. Some people get first information from the lecturers straight forward, someone might require to read before the lecture, someone may need to attend a lecture, he goes back and reads, then will get to know the thing so doing a test, you can't rely on a test....." (Male, medicine student, FGD2).

"........they didn't take into consideration that we are different students, in a different region and our capacity to understand is very different......" (female, Nursing student, FGD3).

\section{Lack of feedback;}

There was a number of participants who despite their appreciation for the essence of the postlecture test, still expressed that the tests somehow did not benefit them due to the fact that they didn't receive feedback to show if they were understanding what was being taught, as said by these participants,

"...........we weren't getting feedback from the previous continuous assessment and the continuous assessment was contributing a point on the final mark........." (Female, Nursing student, FGD3).

"....... the only way me myself I can know whether I have understood or not is when I get the results...okay ..so if you tell me whatever you write for example at the post-test, you ask me a question, I write and I never get the results of that particular test, I can't know if it was right or wrong....." (Male, Medicine student, FGD2).

"...... used to give us pre-lec, after the lecture...test but then we could not get the fee...the feedback so we really could not understand whether our performance was good or poor....." (female, nursing student, FGD3).

\section{DISCUSSION OF THE STUDY FINDINGS}

\section{Resources for Rehabilitation Medicine.}

The study revealed that reading resources for Rehabilitation Medicine are perceived to be insufficient. A number of participants reported having had no textbooks for Rehabilitation Medicine and reported how it was difficult to access information on Rehabilitation Medicine from search engines and educational online databases like Google Scholar. This finding could be due to the fact that with the dearth of information on Rehabilitation medicine, most of the information online is for purchasing rather than open access as is with some other areas of research.

Furthermore, this could also be due to the fact that Uganda is a low resource country and the program is being conducted in a low resource setting as well.

Activities are done during Rehabilitation Medicine

Concerning the activities done during Rehabilitation Medicine training, the findings indicate that 
there are a variety of activities done which included demonstrations, role-plays among others. They have been reported to enhance understanding of the information provided in class. This is in line with Zimmerman et al., (2003) who stresses that activities especially problem-solving tasks help students to understand better and cooperatively work in groups to seek solutions to real-world problems. In addition, a study by Kahl et al., (2013) revealed that students in Malaysia look forward to a more active learning environment especially with problemsolving tasks, projects among others. However, the mode of conduct remains an issue as findings show there is a need to have these voluntarily done by students instead of coercion so as to reduce anxiety and to create a conducive environment for all kinds of learners' personalities ranging from the assertive and confident type to the shy and more introverted students.

Richardson et al., (2010) stressed that student have different personality styles which are positively interrelated with their learning styles and this emphasizes the need for teachers to understand their students' different personality types so as to adjust their teaching to foster individual students' academic success.

\section{Support provided during Rehabilitation Medicine Training}

The study also demonstrated that the support acquired from the lecturers of Rehabilitation Medicine was perceived to be sufficient. The findings further reveal that students consider the lecturers' efforts to engage and ensure understanding by every student in the class and immediate response to inquiries made by students as adequate support.

\section{Evaluation is done during Rehabilitation Medicine Training}

With regard to the evaluation methods employed during the training of Rehabilitation Medicine, there were mixed perceptions regarding the formative assessment. The findings revealed that students consider that the method of evaluation of post-lecture tests that is formative in nature as important as it calls for understanding and stimulates one's thinking. This is similar to the finding from the study done by Al-Kadri et al., (2010) where students expressed a clear preference for formative assessment which was perceived to foster a deeper approach to learning.
Nevertheless, a proportion of students expressed their disagreement with post-lecture tests claiming that they target a specific group of students that understand firsthand from class yet student learning styles are diverse.

The findings also demonstrated the perception of the post-lecture tests as biased since students are not subjected to similar conditions while attempting these tests. This shows that there is a need for an evaluation method that is perceived as neutral to all students.

In addition according to study findings, the postlecture tests would be perceived as useful by the students if the feedback is provided so that students can be in place to assess themselves and improve accordingly. This is further stressed by Nahadi et al., (2015) showed that the application of feedback in formative assessment has a positive impact on the learning process, creates optimism, and boosts students' confidence.

\section{Conclusion}

There were thirteen categories that emerged under the four themes of Resources for Rehabilitation Medicine, Activities done during Rehabilitation Medicine training, the support provided during Rehabilitation Medicine, and Evaluation done during Rehabilitation Medicine training. The qualitative findings suggest that students' perceptions of Rehabilitation are generally positive.

The teaching resources for Rehabilitation Medicine are sufficient although reading resources are perceived as insufficient. A variety of activities done during Rehabilitation Medicine training like problem-solving tasks, demonstrations, and role-plays are perceived as important in enhancing understanding. These however need to be more student-friendly and voluntary.

Whereas formative assessment in the form of post-lecture tests is perceived as relevant and important, there is a need for feedback to be provided to allow student self -assessment.

\section{Study limitations}

Very few fourth-year medical students were available for data collection due to the Covid-19 pandemic.

The researcher would have wished to interview the lecturer of Rehabilitation Medicine but was not in a position to. 
The study involved participants from one university and so findings may not be generalizable to all universities.

\section{Implications and recommendations of the study}

\section{Education}

The negative perceptions of students regarding the evaluation methods employed and the way of conduct of these studies need to be addressed by educators. There is a need for educators to provide continuous feedback/results on their progressive tests so as to promote self-assessment and intensive academic efforts.

\section{Practice}

The perceptions held by students toward a specialty can greatly influence their learning and performance in the clinical area. There is a need to address these negative perceptions during training to secure better practices of taught skills.

\section{Policy}

Students' perceptions strongly influence their performance, learning, and practices as future healthcare professionals. Policymakers need to put the focus on the teaching of Rehabilitation Medicine in institutions of Higher learning. There's a need for designing policies that allow early exposure of students to the principles of Rehabilitation Medicine so as to improve their perceptions.

\section{Areas of further research}

1) A similar study should be carried out to explore nursing and medical students' knowledge and practice of Rehabilitation Medicine principles during their clinical rotation.

2) A study should be done to assess students' attitudes towards dealing with patients with disabilities.

3) A study should be done to explore lecturers' and students' perceptions of formative evaluation in Rehabilitation Medicine.

4) A similar study can be done in other universities to explore nursing and medical students' perceptions of Rehabilitation Medicine in order to compare results and influence policy.

\section{Acknowledgements}

I would like to thank my supervisors, Ms. Josephine N Najjuma and Ms. Hanifah Nantongo for the profound contributions made towards this research.

I also extended my gratitude to the Nursing and Medical students at Mbarara University of Science and Technology for sparing their time to take part in the research study.

My sincere gratitude goes to my father Mr. Lutaaya Jacob and mother Ms. Ndagire Edinansi for the social, emotional, and financial support extended to me.

I would like to thank Madam Catherine Atuhaire for all the guidance and support granted towards seeing this course unit to completion.

\section{LIST OF ACRONYMS AND ABBREVIATIONS}

MUST- Mbarara University of Science and Technology

PMR-Physical Medicine and Rehabilitation

RM- Rehabilitation Medicine

WHO- World Health Organization

\section{DEFINITION OF TERMS}

Bachelor of Science in nursing directs- Program per taken by nursing students that have enrolled right from high school.

Bachelor of Science in nursing completionProgram took by nursing students who have enrolled from a diploma level to a bachelor's level.

Faculty of medicine- A faculty in MUST comprising of medical-related courses.

Medical students - Students pursuing the program, bachelor of medicine, and surgery at MUST.

Rehabilitation medicine- A module done by medical and nursing students in their 4th year, a specialty of medicine that deals with restoration to normal or near Normal of a person who has had an illness, disease, or disorder through a number of specially designed treatments.

\section{A References:}


1) Al-Kadri, H.M.F., Al-Moamary, M.S. \& Van der Vleuten, C. (2009). Students' and Teachers' perception of Clinical assessment program: A Qualitative study in a PBL curriculum. BMC Res Notes, 2(263), pp10-25. http s://doi.org/10.1186/1756-0500-2-263 PMid:20030842 PMCid:PMC2804577

2) Brane, L.B., Carson, R., Susmarski, A.J., Lewno, A.J. \& Dicianno, B.E. (2016) "Changing perception; outcomes from a Physical Medicine and Rehabilitation medical student interest fair." Am J Phys Med Rehabil, pp1-5. https://doi.org/10.1097/PHM.0000000000000583 PMid:28415072

3) Burns, N., \& Groves, S.K. (2003). The practice of nursing research: Conduct, Critique and Utilization, Toronto: WB Saunders.

4) Ferreira, A. \& Santoso, A. (2008). Do student perceptions matter?: a study on the effect of students' perceptions on academic performance. Accounting and Finance, 48(2), pp209-231. https://doi.org/10.1111/ j.1467-629X.2007.00239.x

5) Gibson, C.J., Lin, X., Clarke, K., Fish, H. \& Phillips, M. (2010). Teaching medical students rehabilitation medicine. Disability and Rehabilitation, 32(23), pp1948-1954. https://doi.org/10.3109/09638281003797364 PMid:20441413

6) Grutenbrunner, C., Schiller, J., Schwarze, M., Fischer, V., Paulmann, V., Haller, H. \& Kuther, G. (2010). Hannover model for the implementation of Physical and Rehabilitation Medicine training in Undergraduate medical schools. J Rehabil Med, 42(3), pp206-213. https://doi.org/10.2340/16501977-0513 PMid:20411213

7) Kahl, C. (2013). A deeper lecturers' and Students view of a sustainable Learning Requirement in Tertiary Education in Malaysia. International Journal for Cross-Disciplinary Subjects in Education, 4(2), pp1-10. https: //doi.org/10.20533/ijcdse.2042.6364.2013.0161

8) Khosrawi, S., Ramezanian, H. \& Mollabashi, R. (2018). Survey of medical students' attitude and knowledge towards Physical Medicine and Rehabilitation in Isfahan University of Medical Sciences. J Edu Health Promot, 7(51). https://doi.org/10.4103/jehp.jehp_180_16 PMid:29693032 PMCid:PMC5903171

9) Polit, D., \& Beck, C. (2012), Nursing research: Generating and assessing evidence for nursing practice, Philadelphia, PA: Wolters Kluwer.

10) Richardson., Rita C., Arker \& Emily., (2010). Personalities in the Classroom: Making the Most of Them. Kappa Delta Pi Record, v46 n2 p76-81 Win 2010. https://eric.ed.gov/?id=EJ898402 https://doi.org/10.1080/0 0228958.2010 .10516698

11) Tederko, P., Krasuski, M., Lyp, M., Cabak, A., Bialozewski, D., Stanislawska, I. \& Tarnacka, B. (2018). Perception of the role of physical and Rehabilitation Medicine among Physiotherapy students. J Rehabil Med, 50(7), pp661-667. https://doi.org/10.2340/16501977-2360 PMid:30003266

12) Tederko, P., Krasuski, M., Nyka, I. \& Denes, Z. (2015). Knowledge of Physical and Rehabilitation Medicine among Physicians and medical students. Wiad Lek, 68(2), pp123- 131.

13) Vlak, T., Beban, M., Golja, N.F. \& Eldar, R. (2004). Teaching Disability and Rehabilitation Medicine at the medical school in Split, Croatia. Croatian Medical Journal, 45(1), pp99-102.

14) WHO., (2014), Chapter 4: Rehabilitation, [accessed on 21 December 2019], < https://www.who.into/worl d- report- on- disability/rehabilitation>

15) Zimmerman, A., Lima, M. \& Christy, A.D. (2003). Student centered Learning Activities. American Society of Agricultural and Biological Engineers, 10, pp10-21. 